\title{
A EFETIVAÇÃO DO IDEÁRIO RESTAURATIVO A PARTIR DA APLICAÇÃO DAS PRÁTICAS RESTAURATIVAS
}

Carolina Ellwanger ${ }^{1}$

RESUMO: O artigo apresenta como objetivo apresentar as principais práticas restaurativas oriundas da Justiça Restaurativa, que pressupõe o trabalho para a responsabilização com a recomposição entre os envolvidos e o tratamento das consequências conflitivas, tendo como foco o empoderamento das partes. Visando analisar se as dinâmicas das práticas restaurativas são capazes de concretizar os ideários restaurativos, o trabalho utilizou o procedimento metodológico qualitativo, a partir de pesquisas bibliográficas. Como conclusão, se depreendeu que os círculos de construção de paz, as conferências de grupos familiares, a metodologia SulAfricana Zwelethemba e os encontros vítima-ofensor, geram empatia, empoderamento e alinhando-se com a lógica restaurativa.

Palavras chave: Consenso; Ideário restaurativo; Justiça restaurativa; Pacificação; Prática restaurativa.

\section{THE EFFECTIVENESS OF THE RESTAURATIVE IDEAL FROM THE APPLICATION OF RESTAURATIVE PRACTICES}

\begin{abstract}
The article aims to present the main restorative practices arising from Restorative Justice, which presupposes work for accountability with the recomposition between those involved and the treatment of conflicting consequences, focusing on the empowerment of the parties. Aiming to analyze whether the dynamics of restorative practices are capable of realizing restorative ideas, the work used the qualitative methodological procedure, based on bibliographic research. In conclusion, it emerged that peace-building circles, family group conferences, South African Zwelethemba methodology and victim-offender meetings, generate empathy, empowerment and align with the restorative logic.
\end{abstract}

Keywords: Consensus; Restorative idea; Restorative justice; Pacification; Restorative practice.

\section{INTRODUÇÃO}

\footnotetext{
${ }^{1}$ Doutora em Direito pela Instituição Toledo de Ensino - ITE/SP. Mestre em Direito pela UNISINOS/RS. Professora no curso de Direito da Fundação Universidade Federal de Mato Grosso do Sul (UFMS), campus Três Lagoas. Mediadora certificada pelo TJ/PR e Facilitadora de Círculos Restaurativos certificada pela Escola da Magistratura do Paraná - EMAP. E-mail: carolellwanger@yahoo.com.br
} 
O movimento restaurativo surge na seara penal como mecanismo capaz de incluir a vítima na resolução do delito. Baseia-se no reconhecimento de que o sistema punitivo tradicional se concentra excessivamente nos papéis de atores estatais (policial, promotor, juiz) e na figura do acusado, ao mesmo tempo em que remete a considerações abstratas a respeito da transgressão ou não da norma pelos fatos ocorridos no passado se ocupando de reconstituir para então punir.

Esse procedimento coloca a vítima à margem do processo, e, sobretudo, deixa a descoberto os danos materiais e psicológicos produzidos pela infração. Ao desviar a atenção do dano, a justiça retributiva tende a eliminar a responsabilidade emocional do infrator, não facilitando a pacificação e produzindo como principal efeito a amplificação dos conflitos e a reverberação da violência.

Diferentemente, a justiça restaurativa configura-se como mecanismo de recomposição entre as partes afetadas pelo delito que busca uma real reinserção do infrator na sociedade, através da responsabilização e restauração.

A lente restaurativa surge, portanto, da necessidade de um outro olhar para o conflito penal, um outro modo de responder ao fenômeno criminal e busca uma menor incidência da intervenção punitiva do Estado. Contudo, essa diminuição não se vincula a um enfraquecimento do papel estatal na reação ao crime: mas, sim, uma nova incumbência do Estado em lidar com a litigiosidade.

O crime é um problema social e comunitário. Problema "da" comunidade, que nasce "na" comunidade e nela deve encontrar as fórmulas positivas para as soluções, alcançando todo o espectro social. Conquanto comunitário, o crime é um problema humano e, portanto, a resposta é alcançada pela empatia para com o infrator. Ressalta-se que empatia não é sinônimo de simpatia, nem de cumplicidade, porém apreço pelo drama humano.

Colocar-se no lugar do infrator gera o entendimento dos reais motivos que levaram ao delito. Sabendo as causas, aumenta a viabilidade de se trabalhar na raiz do problema, buscando com isso a verdadeira reinserção do ofensor no meio comunitário e a definição da melhor maneira para a restauração.

Para atingir os propósitos restaurativos, realiza-se o tratamento do conflito através das práticas restaurativas. As práticas restaurativas se embasam em três concepções: encontro, reparação e transformação. O encontro realça a liberdade de manifestação dos envolvidos para o tratamento do conflito. A reparação visa trabalhar as consequências do ato lesivo. E a 
transformação enfatiza a construção coletiva dos ideários de justiça, com fundamento nas experiências dos envolvidos e na necessidade de responsabilização.

O artigo apresenta como tema a análise das principais práticas restaurativas, apresentando conceitos, metodologias e exemplos de aplicação. Como problema de pesquisa busca-se entender se as práticas restaurativas são capazes de concretizar os ideários restaurativos.

Como procedimento metodológico, a presente pesquisa é considerada qualitativa, pois se pretende compreender fenômenos de ordem subjetiva, buscando sua abrangência. A técnica de pesquisa bibliográfica tem como fontes de consulta: livros, revistas, periódicos, artigos e publicações avulsas pertinentes ao tema.

\section{JUSTIÇA RESTAURATIVA: APROXIMAÇÃO CONCEITUAL}

A justiça restaurativa surge do e no elo comunitário. Para conceituar a justiça restaurativa, necessita-se ter claro que ela se configura como uma inversão do objeto. Esse é o ponto de partida da definição. O foco dessa justiça ocorre nas relações afetadas pelo ato delituoso e nas consequências do crime. Nesse sentido:

O ponto de partida para o novo é a inversão do objeto. Assim, o objeto da justiça restaurativa (e do saber que se pretende construir ao seu redor) não pelo crime em si, considerado como fato bruto, nem a reação social, nem a pessoa do delinquente, que são os focos tradicionais da intervenção penal. A justiça restaurativa enfoca as consequências do crime e as reações sociais afetadas pela conduta. (SICA, 2007, p. 27-28)

Desse modo, a justiça restaurativa é apresentada como forma de composição entre as partes afetadas pelo delito e que busca uma real reinserção do criminoso na sociedade, sem que esse tenha que se enquadrar em um padrão de conduta, ao contrário, possibilita que ele possa criar o seu próprio padrão sem infringir nos direitos alheios.

Um dos elementos centrais da justiça restaurativa é a solidariedade. Ao mesmo tempo que se deve fornecer um tratamento digno ao autor do delito, há de se estender a atenção para a vítima. Absolutamente, todos os envolvidos no delito devem ter a possibilidade de recomeçar. Como esse recomeço será realizado depende do caso concreto.

O ideário restaurativo visa propiciar uma socialização calcada na responsabilização e na reparação. 
A justiça restaurativa oferece processos de diálogo, nos quais todas as pessoas direta ou indiretamente envolvidas, com algum interesse ou necessidade, afetadas pelo cometimento de infração legal, possuem a oportunidade de participar ativamente e coletivamente para resolver as questões derivadas do conflito. As metas desses processos de diálogo são: a responsabilização da(s) pessoa(s) ofensora(s) e a reparação das vítimas.

A reparação às vítimas muitas vezes pode ser simbólica. O foco maior é colocá-las no centro da atenção. Assim, preocupa-se com as consequências do delito e com os passos a serem dados para minimizar as consequências.

Compreende-se a reparação como algo mais eficaz para a vítima, se comparada com a punição a ser atribuída pelo Estado ao autor do delito. Necessário esclarecer que o procedimento restaurativo não objetiva apenas a reparação material. A vítima é parte central no processo restaurativo, sendo sua voz, narrativa e vontade ouvidas e analisadas.

O conceito de justiça restaurativa para Zehr $(2014$, p. 36) se baseia em três pilares: dano, obrigação e engajamento:

Se ergue sobre três pilares ou elementos simples: os danos e as consequentes
necessidades (de vítimas em primeiro lugar, mas também da comunidade e dos
ofensores); as obrigações (do ofensor, mas também da comunidade) que advêm do
dano (e que levaram ao dano); o o engajamento daqueles que detêm legítimo interesse
no caso e na sua solução (vítimas, ofensores e membros da comunidade).

A justiça restaurativa pode ser vista como um novo paradigma, multidimensional, que gera: a possibilidade de superação do paradigma de justiça punitiva; a personalização a partir do diálogo pessoal direto e indireto entre os protagonistas do evento delitivo; o redescobrimento, o respeito e atenção à vítima; a participação da comunidade; a ampliação das respostas ao delito; o acordo autônomo frente a uma decisão heterônoma e a reparação, a conciliação e a responsabilização.

Logo, o pilar da restauração, proposta pela justiça restaurativa, é a participação dos envolvidos no ato traumático. Essa participação deve ser ativa e criativa, capaz de gerar mútua compreensão e oportunidade de diálogo.

Assim, a justiça restaurativa pode ser definida como sistema baseado em valores que aplica técnicas capazes de gerar reflexão sobre eventos danosos e suas respectivas consequências, proporcionando, a partir da alteridade, a oportunidade da reparação dos danos gerados a todos os envolvidos no conflito.

\section{PRÁTICAS RESTAURATIVAS}


As práticas restaurativas, utilizadas pela justiça restaurativa, projetam-se à proposta de promover entre os verdadeiros protagonistas do conflito criminal, vítima, autor do delito e sociedade envolvida, iniciativa de diálogo com o fim de reparar os danos sofridos pela infração. Segundo Sica (2007, p. 10), "qualquer ação que objetive fazer justiça por meio da reparação do dano causado pelo crime pode ser considerada como prática restaurativa”.

Nesse sentido, Santos (2014, p. 11) afirma que as práticas restaurativas, em virtude de suas especificidades, não se encontram em oposição aos princípios estruturais do direito, pelo contrário, tais práticas podem ser alternativas ou complementares à reação punitivista:

\footnotetext{
Pode acontecer que a obtenção das finalidades restaurativas - através de uma reparação que tem um sentido muito amplo - tenha como consequência a desnecessidade de punição, porque já não existem necessidades preventivas relevantes. Nestas hipóteses, a solução restaurativa do conflito criminal contribuirá para a limitação da intervenção penal, favorecendo o seu caráter de ultima ratio. Noutros casos, porém - sobretudo em alguma da criminalidade mais grave imputada a agentes mais perigosos -, a condenação pode relevar-se indispensável, surgindo a eventual aplicação da justiça restaurativa em moldes que não são os da alternatividade, mas antes os da complementaridade. A possibilidade de práticas restaurativas póssentenciais parece comprovar, nestas hipóteses, a diversidade das finalidades penais restaurativas.
}

As práticas restaurativas são vistas como mecanismos capazes de gerar o senso de responsabilidade no agente infrator. Caso a aplicação das práticas ocasione a reparação na integralidade do dano (e aqui se vislumbra tanto a reparação da vítima quanto à reparação da comunidade e de qualquer outra pessoa que tenha sido prejudicada), seria desnecessária a punição ao agente. Quando não for possível tal reparação, as práticas restaurativas atuariam em caráter complementar ao sistema punitivo.

Na visão de Ferreira (2006), as práticas restaurativas são um processo no qual todas as partes ligadas a uma ofensa penal participam de reuniões que visam resolver coletivamente e consensualmente as consequências práticas da ofensa e de suas implicações no futuro.

As práticas da justiça restaurativa, na visão de Paul McCold e Ted Wachtel (2003), compõem-se de três estruturas conceituais diferenciadas e correlacionadas, sendo elas: a janela de disciplina social, o papel das partes interessadas e a tipologia das práticas restaurativas.

Pela estrutura da janela de disciplina social, tem-se a intercessão entre o nível de controle (disciplina, limites) e apoio (encorajamento, sustento). 
As figuras dentro da sociedade que possuem um cargo de autoridade (professores, pais, autoridades judiciárias e policias, entre outros) necessitam tomar decisões de como manter a disciplina social. Até pouco tempo, a única forma de manutenção dessa disciplina estava baseada na punição; entretanto, mais recentemente, com o avanço da psicologia, vem-se construindo outra forma de manutenção da ordem, baseada substancialmente no apoio. Nesse contexto é que se aplica o conceito da janela de disciplina social.

Cada uma das variáveis (controle a apoio) foi dividida em dois aspectos: alto e baixo. A justiça restaurativa aglomera altos níveis de controle e apoio.

$\mathrm{Na}$ janela da disciplina social, existe a inserção de quatro padrões, cada um sendo caracterizado por uma sigla. Ao padrão com baixos níveis de controle e apoio dá-se o nome de negligente e atribui-se a palavra "nada", posto que nesse modelo a justiça nada faz em resposta ao delito. Na combinação entre um alto nível de controle e baixo apoio, insere-se o conceito de modelo punitivo, sendo caracterizado pela sigla "ao", uma vez que como resposta ao crime há uma reação ao delinquente, punindo-o sem oferecer nenhum tipo de suporte. Já o modelo permissivo é composto por alto apoio e baixo controle, sendo denominado pela palavra "pelo", posto ser feito tudo pelo transgressor, que não irá sofrer sanções, mas terá grande nível de ajuda. O paradigma restaurativo pode ser resumido pela sigla "com", apresentando alto controle e apoio, sendo as práticas restaurativas realizadas com a presença de infratores e vítimas.

Buscando evitar as práticas puramente punitivas ou meramente permissivistas, tem-se a inserção do conceito da janela da disciplina social. Por esta, a Justiça Restaurativa contém alto controle e alto apoio, confrontando e desaprovando as transgressões enquanto afirma o valor intrínseco do transgressor.

Dessa forma, a janela da disciplina social compõe a estrutura das práticas restaurativas, que buscam, com grande nível de apoio ao infrator, que este se responsabilize pelos atos cometidos de modo a restaurar as relações afetadas pelo delito.

As partes interessadas podem ser divididas em duas categorias: as principais partes interessadas e as partes secundárias. Estão dentro da categoria das principais partes interessadas a vítima, o transgressor e as respectivas famílias. São consideradas partes secundárias as pessoas integradas pela sociedade afetada.

A estrutura da restauração necessita da participação ativa das partes interessadas no delito, posto que somente com o diálogo entre essas é que cada uma poderá expressar seus 
pensamentos e sentimentos envoltos pelo crime. A participação, entretanto, deve ser proporcional ao grau de envolvimento com o crime praticado.

Todas as partes interessadas, diretas e indiretas, havendo consenso, são chamadas a buscar, em conjunto, uma solução efetiva para o conflito. O grau de envolvimento das partes na troca emocional e nas decisões definirá se a atuação se enquadra como justiça restaurativa (ou seja, se está inserida assim na janela de disciplina social).

As tipologias das práticas restaurativas dividem-se em práticas totalmente restaurativas, em grande parte restaurativas e parcialmente restaurativas.

As práticas totalmente restaurativas envolvem a vítima, a comunidade e o transgressor e se satisfaz a partir da participação de todos nos círculos de paz, conferências restaurativas e conferências de grupos familiares.

Já as práticas em grande parte restaurativas não apresentam a participação de todos os envolvidos, podendo ser diversificada a partir de três atitudes: do encontro entre transgressor e vítima deve resultar a restituição à vítima e a mediação entre vítima e transgressor; do encontro entre transgressor e comunidade deve ser observada a disciplina positiva, as conferências sem a vítima e ação das comunidades terapêuticas; e por fỉm, do encontro entre a comunidade e a vítima a ocorrência do círculo de apoio a vítima.

No que tange às práticas parcialmente restaurativas, estas se configuram com atendimentos individuais a cada parte interessada, a saber: a vítima recebe o serviço e a compensação pelo crime; a comunidade, o serviço aos familiares do transgressor e o serviço social para as famílias e, por último, o transgressor terá conselhos reparativos, treinamento de sensibilização para o ocorrido com a vítima, além de serviços comunitários relacionados com o ato e painéis de auxílio aos jovens.

Na visão de Zehr (2017, p. 73), a restauração deve ser implementada no modelo possível. Ou seja, muito embora o ideal seria propiciar aos envolvidos as práticas totalmente restaurativas, muitas vezes será possível apenas realizar práticas parcialmente restaurativas. $\mathrm{Na}$ ocorrência disso, já existirá um avanço. O que deve permear os tratamentos dos conflitos é a possibilidade da restauração, qualquer caminhar nesse sentido já irá se configurar como um avanço social:

Talvez uma meta realista seja avançarmos tanto quanto possível na direção de um processo restaurativo. Em alguns casos ou situações pode ser que não se consiga chegar muito longe. Em outros, chegaremos a processos e soluções verdadeiramente restaurativos. Entre um extremo e outro, haverá muitas instâncias e situações em que 
os dois sistemas deverão ser utilizados, e a justiça será feita de modo apenas parcialmente restaurativo.

As práticas restaurativas visam humanizar as relações entre os envolvidos, recompondo as situações advindas com o delito e (res)socializando de fato o criminoso.

A autora Pranis (2010) traz como ponto essencial das práticas restaurativas os círculos de construção de paz. Tais círculos se espelham nos tradicionais círculos de diálogo dos povos indígenas da América do Norte. Reunir-se numa roda para discutir questões é comum na história da humanidade, a utilização desse modo de diálogo na justiça criminal ganha destaque a partir do trabalho iniciado em Yukon, Canadá, na década de 1990.

\subsection{OS CÍRCULOS DE CONSTRUÇÃO DE PAZ}

Um círculo de construção de paz é meio de reunir pessoas de modo que todos sejam igualmente respeitados, tenham igual oportunidade de falar sem interrupção, se expliquem contando a própria história, sejam tratados com igualdade, e que o aspecto emocional de todos seja igualmente acolhido.

Os círculos são úteis, especialmente, quando duas ou mais pessoas necessitam tomar decisões conjuntas, discordam, precisam tratar experiência que resultou em danos, desejam trabalhar em conjunto como equipe, querem partilhar dificuldade ou objetivam aprender uns com os outros:

Num círculo, chega-se à sabedoria através das histórias pessoais. Ali a experiência
vivida é mais valiosa do que os conselhos. Seus integrantes partilham experiências
pessoais de alegria e dor, luta e conquista, vulnerabilidade e força, a fim de
compreender a questão que se apresenta. Quando alguém conta uma história, mobiliza
as pessoas à sua volta em muitos níveis: emocional, espiritual, físico e mental. E os
ouvintes absorvem as histórias de modo muito diferente do que se estivessem ouvindo
conselhos. (PRANIS, 2010, p. 28)

Os círculos de construção de paz são fortes o suficiente para conter sentimentos como raiva, frustação e alegria, além de trabalhar com a verdade, conflitos, paradoxos, visões de mundo diferentes, silêncio e dor:

Os círculos se valem de uma estrutura para criar possibilidades de liberdade: liberdade para expressar a verdade pessoal, para deixar de lado as máscaras e defesas, para estar presente como um ser humano inteiro, para revelar nossas aspirações mais profundas, para conseguir reconhecer erros e temores e para agir segundo nossos valores mais fundamentais. (PRANIS, 2010, p. 25)

A estrutura básica do círculo consiste em os participantes se sentarem em cadeiras dispostas em roda, sem nenhuma mesa no centro ou objeto alto que dificulte a visão entre os 
presentes. A partir de dinâmicas, o objetivo é permitir que os envolvidos se expressem livremente e encontrem um espaço seguro para delimitar erros e temores, juntados os valores que cercam a humanidade.

O encontro dos valores individuais daqueles que pertencem ao círculo demonstram como os seres humanos estão unidos (mesmo que desconheçam essa ligação). Os valores da humanidade perpassam por dar sentido à vida, à sociedade, aos interesses sociais, à razão e ao amor, e, portanto, são transmitidos indistintamente entre gerações. Os valores da humanidade "podem unir, sejam quais forem as nossas raças ou as nossas religiões, (...) podem permitir-nos viver em conjunto" (MORIN, 1996, p. 152)

Uma das primeiras fases dos círculos consiste no compartilhamento dos valores entre os presentes. Muito embora não existam respostas prontas para quais valores serão apresentados nos círculos, é muito comum a ocorrência de valores como: honestidade, humanidade, coragem, inclusão, empatia, perdão, amor e respeito.

A conexão entre os integrantes do círculo inicia-se com os valores, mas alastra-se durante todo o procedimento circular. Não há a necessidade de se reinventar os valores (aquilo que realmente importa na sociedade), mas há a necessidade de trabalhar com fidelidade a eles:

\footnotetext{
Não se trata de inventar novos valores, trata-se de inventar uma nova fidelidade aos valores que recebemos e que temos o encargo de transmitir.

A passagem com que somos historicamente confrontados e socialmente obrigados não é a passagem de uma escala de valores para outra, como julgava Nietzsche. Quem considera ultrapassados os valores de Sócrates, de Jesus ou de Buda, os valores de Montaigne ou de Espinosa, os valores de Voltaire ou de Victor Hugo? A passagem que nos reclamam é a da fé à fidelidade. (...) Fidelidade, por fim, à humanidade e aos direitos do homem. (MORIN, 1996, p. 153)
}

O processo de construção de valores é apenas um dos meios utilizados no círculo para gerar a interconfiança e interdependência. Os valores, que demonstram aquilo que cada ser humano possui de melhor, são capazes de evidenciar o quanto os seres humanos são semelhantes entre si, e justamente por isso podem aprender e auxiliar-se mutualmente.

A restauração proposta pela justiça restaurativa pressupõe que todos os envolvidos em qualquer tipo de evento serão afetados de alguma maneira pelo acontecimento. E isso ocorre tanto em bons ou maus momentos:

Um desses ensinamentos que embasam o processo em círculo é a afirmativa de que tudo no Universo está ligado, e que é impossível isolar algo e agir sobre aquilo sem atingir o resto. Segundo esta visão de mundo, não existe o que chamamos de “observador objetivo" ou "perspectiva isenta". Tudo está conectado. (PRANIS, 2010, p. 41) 
Os círculos de construção de paz demonstram a responsabilidade que cada um tem no todo, conectando tanto no plano individual quanto grupal. Para a compreensão de como os círculos são realizados e visando delimitar o desenvolvimento do círculo como técnica, passase a análise das fases circulares.

\subsubsection{Antes, durante e depois: as fases circulares}

Os círculos desenvolvem-se através de quatro grandes estágios: o primeiro estágio avalia a possibilidade de aplicação do círculo; o segundo estágio consiste em realizar a preparação para a aplicação das técnicas; o terceiro estágio é realizado através do encontro com as partes; e o quarto e último estágio consistem no acompanhamento ${ }^{2}$.

O terceiro estágio é marcado pela construção do círculo, contudo, trabalhos circulares podem ocorrer nas demais fases, a depender do assunto a ser tratado. Dessa forma, o primeiro e o segundo estágio representam a fase pré-círculo, o terceiro estágio, a fase circular e o quarto estágio, o pós-círculo.

A fase pré-círculo é marcada pela verificação das possibilidades para a ocorrência do círculo. Deve ser verificado se os envolvidos pretendem participar, bem como se há

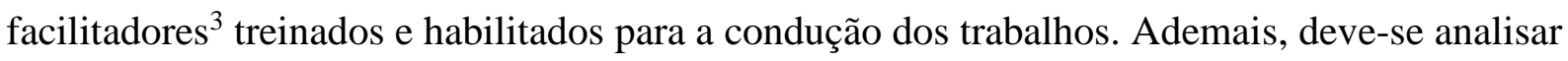
se há a necessidade de criação de sistema de apoio para o ofensor e para a vítima. Assim, é

\footnotetext{
${ }^{2}$ Segundo Kay Pranis, no primeiro estágio são realizadas as seguintes perguntas: As partes principais estão dispostas a participar? Há possibilidade de facilitadores treinados? A situação permite o tempo necessário para aplicação do processo em círculo? A segurança física e emocional dos envolvidos pode ser garantida? No seguindo estágio, deverão ser identificadas as partes que irão participar do círculo, a partir das respostas as seguintes perguntas: Quem sofreu os impactos da situação? Quem tem os recursos, habilidades, conhecimentos necessários? Quem tem experiência de vida similar que possa representar uma contribuição? Ademais, na segunda fase devese começar a estudar o contexto do problema. A terceira fase visa: identificar os valores partilhados e desenvolver os princípios norteadores; iniciar a contação de histórias a fim de criar relacionamentos e conexões; partilhar preocupações e esperanças; expressar sentimentos; examinar as causas subjacentes do conflito ou danos; gerar ideias para sanar os danos e resolver conflitos; determinar as áreas de consenso para agir; e, desenvolver acordos e explicitar responsabilidades. No quarto estágio deve-se avaliar o progresso dos acordos; examinar as causas de qualquer descumprimento de obrigações, esclarecer as responsabilidades e identificar os próximos passos, caso o descumprimento persista; adaptar os acordos conforme a necessidades; e, celebrar o sucesso. (PRANIS, 2010, p. 61-62)

${ }^{3}$ Enquanto na mediação o terceiro que auxilia os trabalhos é chamado de mediador; nas dinâmicas circulares da justiça restaurativa esse é chamado de facilitador. Isso ocorre porque o facilitador possui um trabalho mais participativo se comparado com o mediador. No círculo de construção de paz não há expectadores, sendo assim, o facilitador conduz os trabalhos, mas também participa da construção do ambiente seguro. Por exemplo, o facilitador também expõe os seus valores. Obviamente, na resposta de algumas perguntas o facilitador não participará, uma vez que não possui relação com os atos tratados no círculo.
} 
possível realizar, de maneira separada, círculos visando à recuperação da vítima e círculos de compreensão do ofensor.

A fase circular utiliza cinco elementos estruturais: cerimônia, orientações, bastão da fala, facilitação e decisões consensuais. (PRANIS, 2010)

O círculo inicia com uma cerimônia de abertura, que, além de marcar o começo do círculo, convida os integrantes a se conectarem uns aos outros como partes de um mesmo grupo. O foco é estabelecer uma mudança na atenção dos participantes: deixam-se de lado as atenções do dia a dia para focar-se integralmente nas atividades do círculo.

Um segundo passo é realizar as orientações, que consistem nos compromissos assumidos pelos integrantes do círculo. Nesse momento é que são colhidos os valores do grupo e criam-se as diretrizes para o trabalho circular. Cada integrante do grupo irá apresentar seu(s) respectivo(s) valor(es). Esses valores (listados em papéis) devem ser alocados no centro do círculo, pois é nesse espaço que se cria o elo entre todos os participantes. As diretrizes de trabalho devem ser construídas conjuntamente entre os presentes, já que representaram a maneira como o trabalho será realizado. Sugere-se como diretrizes básicas a confidencialidade (para que todos fiquem à vontade para expressar o sentimento) e a escuta ativa (que é a atenção total aquele que fala).

O bastão da fala é o objeto que passa por todas as pessoas. Possui como característica ser algo de valor para aquele grupo. O objetivo desse objeto é marcar o momento e o respeito pela fala de cada integrante do grupo. $\mathrm{O}$ bastão passa entre todos demonstrando que aquele que possui o objeto é o indivíduo que receberá toda a atenção do grupo e poderá livremente se expressar.

O facilitador será responsável pela realização das perguntas norteadoras. São essas perguntas que serão feitas e que os integrantes do grupo irão responder quando estiverem com o bastão da fala. O facilitador irá preparar as perguntas visando à reflexão profunda dos integrantes do círculo e a construção da empatia entre os presentes. Nesses questionamentos, é muito útil a contação de histórias. A partir das experiências de vida, facilita-se a empatia, pois a escuta passa ser integral, já que há um visível relaxamento em quem escuta uma história. Ademais, é possível vislumbrar as dificuldades e facilidades que cada integrante possuiu ao longo da vida, sendo comum o espelhamento em partes dessas histórias.

Ao longo das rodadas de fala do círculo, o facilitador deve propiciar que os envolvidos se conheçam através dos pontos fortes e fracos que cada um possui. O reconhecimento tem que 
ser a partir da humanidade, com suas dificuldades e facilidades. Quando as partes estiverem empoderadas e o senso de grupalidade tiver aflorado, se trabalha os consensos sobre a responsabilização, a recomposição a ser feita com as pessoas envolvidas e a restauração dos atos e do tecido social abalado.

Por fim, a cerimônia de encerramento serve para reconhecer o esforço realizado no círculo. Além de reafirmar a conexão entre os presentes, visa demonstrar a esperança para o futuro.

O pós-círculo é utilizado para aferir se a restauração proposta estará de acordo com a capacidade de agir daquele que irá reparar. O ato restaurar não pode ser impossível de ser realizado, ao passo que deve propiciar certo esforço. O denominado "esforço reparador" (SUMALLA, 2012, p. 61) é útil para atribuir valor ao ato da reparação, de modo que permita compensar o desvalor causado pela ação delitiva.

\subsubsection{Tipos e utilização dos círculos}

Os círculos de construção de paz podem ser utilizados em vários contextos e com inúmeras finalidades: para dar apoio e assistência a vítimas de crimes; sentenciar menores e adultos infratores; reintegrar egressos do sistema prisional; dar apoio e monitorar ofensores crônicos em liberdade condicional; gerar suporte para famílias acusadas de negligência ou maus tratos a crianças e, ao mesmo tempo, garantir a segurança das crianças; formação de equipes; desenvolvimento de programas governamentais; lidar com discriminação, assédio e conflitos interpessoais no local de trabalho; tratar de desentendimento entre vizinhos; tratar conflitos escolares; ensinar; tratamento de conflitos familiares; chorar a perda de uma família ou comunidade; lidar com disputas ambientais; entre outras. (PRANIS, 2010)

É possível dividir os círculos restaurativos conforme o grau de complexidade.

São exemplos de círculos com menor complexidade: círculos de celebração; círculos de diálogo e aprendizagem; círculos de construção de senso comunitário; círculos de fortalecimento de vínculos familiares; e, círculos de fortalecimento de vínculos da equipe de trabalho. Nesses círculos, por exemplo, é possível aos participantes explorarem questões a partir de um grande leque de pontos de vistas, permitindo que todas as vozes sejam ouvidas. É possível também criar laços e construir relacionamentos, além de oferecer apoio a ações coletivas criando responsabilidades mútuas aos participantes. 
Já os círculos de maior complexidade poderiam ser classificados como: círculos de superação de traumas; círculos de tomada de decisão; círculos de reintegração; círculos de suporte e apoio; e, círculos de conflito. Tais círculos possuem como objetivo reunião de pessoas incluídas em disputas ou até mesmo com pessoas que passam por grandes dificuldades e necessitam de suporte comunitário para superar traumas. Além disso, são esses círculos que podem ser utilizados para pessoas que serão colocadas em liberdade do sistema prisional, a fim de reconstruir ligações e integrar o indivíduo.

O círculo restaurativo, em especial o círculo conflitivo, propicia oportunidade para que vítima e comunidade possam rever a desresponsabilização. Em virtude do ressentimento, é muito corriqueiro a vítima desumanizar o ofensor, contudo, o encontro circular poderá demonstrar as vulnerabilidades deste, propiciando a facilitação da recomposição. (BOONEN, 2011)

Nos círculos de celebração, diálogo, construção de senso comunitário e fortalecimento tem-se que determinada questão é analisada sobre vários pontos de vista. Nesses círculos, não se vislumbra, necessariamente, um consenso, mas sim possibilitar que todas as pessoas tenham oportunidade de expressar o ponto de vista e estimular na comunidade uma reflexão a partir da pluralidade de opiniões.

O círculo de compreensão objetiva desenvolver uma análise completa de determinado contexto, situação ou comportamento. Empenha-se o esforço para a compreensão de algum(s) aspecto(s) difícil(eis) de um conflito.

Já o círculo de restabelecimento tem como foco auxiliar uma pessoa ou grupo que passou por uma grande perda ou trauma. Desse círculo poderá ser criado um plano de ajuda.

O círculo de apoio reúne pessoas capazes de oferecer auxílio para as vítimas e agressores. Normalmente, se reúne por um período e trabalha a partir do consenso para desenvolver acordos e planos.

Os círculos de resolução de conflitos visam reunir pessoas que passaram por alguma divergência para tratar as origens e consequências do conflito. O foco é a recomposição e restauração, gerando como consequência um acordo consensual.

Os círculos de reintegração objetivam reinserir um indivíduo ou grupo de foi afastado do convívio social, visando a aceitação integral por parte da comunidade. 
Ferrão, Santo e Dias (2016) apresentam outros dois tipos de círculos utilizados na Unidade de Internação de adolescentes em conflito com a lei de Santa Maria/RS: círculos familiares e círculos de compromisso.

Nos círculos familiares, não há a participação da vítima, somente do infrator, sua família e comunidade. Desse encontro nascem propostas alternativas para a reparação dos danos causados.

O círculo de compromisso é considerado uma variação do círculo familiar e configurase como uma espécie de "ritual de passagem", já que ocorre durante a fase de planejamento para o desligamento do infrator da unidade em que cumpre a medida de segurança.

Como nos demais métodos circulares, o círculo de compromisso se desenvolve a partir das etapas do pré-círculo, círculo e pós-círculo. No pré-círculo, o adolescente indica quais pessoas são fundamentais na vida que será reiniciada fora da instituição, após o fim da privação de liberdade. No círculo, ocorre a reunião de todas as pessoas indicadas pelo menor, bem como o próprio menor e as representantes da instituição que farão o acompanhamento do menor após o término da medida socioeducativa. Nesse círculo, são convencionadas atitudes e ações que visem possibilitar a reinserção do jovem na comunidade e no seio familiar. O pós-círculo é realizado pela instituição que irá acompanhar o adolescente quando acabar o cumprimento da medida socioeducativa, e visa avaliar junto com os propositores das ações se essas estão sendo suficientes e se estão de fato sendo implementadas.

\subsection{CONFERÊNCIAS DE GRUPOS FAMILIARES}

Outro tipo de prática restaurativa é a conferência de grupos familiares.

A conferência familiar é espécie de prática restaurativa que nasceu na Nova Zelândia com o projeto Children, Young Personsand Their Families Act, em 1989.

O modelo do projeto visa implicar todas as pessoas afetadas, de alguma forma, pelo delito em um procedimento de tomada de decisão sobre qual a melhor maneira de responder a esse delito. As conferências podem ocorrer por iniciativa do Ministério Público ou da polícia e funcionam, em grande parte, no âmbito da justiça juvenil. (ACHUTTI, 2016) 
As facilitações das conferências são realizadas por autoridades devidamente treinadas para tal finalidade ${ }^{4}$, visando fazer o papel de tribunal. Assim, no final das conferências, tem-se um plano completo para jovens que cometeram ofensas, sendo estipulados elementos de prevenção e punições. O plano final precisa ter a concordância de todos, sendo que a vítima, o ofensor e a polícia podem vetar a decisão se não estiverem satisfeitos.

Tal prática restaurativa foi aplicada no Brasil nos municípios de São Caetano do Sul/SP e São Paulo/SP no ano de 2010 no projeto "Novas Metodologias de Justiça Restaurativa com Adolescentes e Jovens em Conflitos com a Lei”, financiado pelo Centro de Direitos Humanos e Educação Popular de Campo Limpo. (MEIRELLES \& MARIONI, 2014)

O projeto foi considerado satisfatório uma vez que todos os relatos dos participantes demonstraram a valorização pela experiência. Os casos levados para as conferências seguiram os seguintes critérios: a) roubo cometido com grave ameaça sem o uso de arma de fogo; b) família do adolescente realizava o acompanhamento do menor; c) consentimento da família e do adolescente para participar do projeto; d) perfil do adolescente que indicava abertura para o diálogo; d) os casos de coautoria só eram admitidos se ambos fossem adolescentes e cumprissem os critérios; e) quando o caso já estava na execução, o julgamento teria de que ter determinado liberdade assistida e reparação de danos.

O procedimento restaurativo iniciou com os coordenadores realizando préconferências. Os trabalhos eram iniciados com reuniões, separadamente, com o ofensor e a família para dialogar sobre o procedimento e quais pessoas deveriam ser chamadas para participar da conferência. Em um segundo momento, se reuniam com a vítima para verificar se ela aceitava participar, nessa oportunidade era explicado os direitos da vítima e era garantido a segurança para que não ocorresse revitimização.

Nas conferências eram mencionados os aspetos legais, sendo realizada a leitura do ato infracional e das acusações. Na sequência se compartilhava informações, analisando os comportamentos e impactos do ato infracional na vida dos envolvidos. Para isso o coordenador seguia o seguinte roteiro:

- Ler um resumo dos fatos que deve estar baseado na acusação;

\footnotetext{
${ }^{4}$ Nesse sentido: “As conferências são organizadas e facilitadas por assistentes sociais pagos pelo Estado, chamados de Coordenadores de Justiça e Adolescente. É sua função ajudar as famílias a determinar quem deve estar presente no encontro, e a criar o processo mais apropriado para aquele grupo em particular. Um dos objetivos do processo é sua adequação cultural, e a forma do encontro precisa estar adaptada às necessidades e à cultura de todos os envolvidos." ZERH, Howard. Justiça Restaurativa. Trad. Tônia Van Acker. $2^{a}$ ed. São Paulo: Palas Athena, 2017, p. 68.
} 
- Perguntar se o ofensor assume a culpa, pois a conferência só acontece quando o jovem admite a responsabilidade pelo ato ou quando já há comprovação da referida responsabilidade;

- Conferir se o jovem entendeu a acusação e o seu significado. Deve ser dito ao ofensor, que não assuma uma acusação que não tenha cometido;

- Pedir à vítima que fale do impacto que o ato causou a ela. Como o coordenador já sabe que a vítima vai falar, pois já tratou disto na pré-conferência, ele formula as perguntas de forma a facilitar a fala da vítima. Abrir espaço para expressão de emoções;

- Sumarizar o impacto causado à vítima;

- Pedir que o ofensor fale sobre o ato que cometeu;

- Sumarizar o que foi dito até o momento;

- Perguntar ao ofensor como ele se sente com relação ao que ouviu da vítima;

- Abrir espaço para ele falar com a vítima se assim desejar;

- Buscar estabelecer a comunicação entre vítima e o ofensor;

- Pedir para a família do ofensor falar a respeito do impacto causado pelo ato;

- Abrir espaço para eles falarem sobre o que querem da conferência, o que gostariam de falar do filho ou questões que queiram fazer;

- Incluir a contribuição dos demais suportes. (MEIRELLES \& MARIONI, 2014, P. 239-240)

Após o momento de fala e escuta, com a validação de sentimentos entre todos os envolvidos, passa-se a realizar o caucus - reunião privada do ofensor com os respectivos familiares. Durante o caucus, será debatida a prévia do plano de ação a ser apresentado à vítima. O objetivo das reuniões privadas é rever as necessidades do infrator e qual apoio ele irá necessitar para cumprir o plano de trabalho.

O último momento da conferência é utilizado para que o grupo, novamente reunido, dialogue visando o estabelecimento do plano final de trabalho. O objetivo é encontrar uma solução capaz de atender às necessidades dos envolvidos e que possa ser, verdadeiramente, cumprido.

A pós-conferência é utilizada para acompanhar e monitorar o cumprimento do plano de ação, além de possibilitar às partes o diálogo para eventuais ajustes no planejamento definido.

Na experiência realizada nos municípios de São Caetano do Sul/SP e São Paulo/SP, observou-se que os planos construídos foram capazes de otimizar três pontos fundantes dos ideários restaurativos: a reparação de danos à vítima; o reforço dos laços familiares e a inserção do adolescente na comunidade com a garantia de seus direitos.

\subsection{METODOLOGIA SUL-AFRICANA ZWELETHEMBA}


A prática restaurativa implementada na África do Sul, denominada Zwelethemba, possui como característica marcante o forte caráter comunitário. Utilizada na comissão da verdade e da reconciliação, foi fundamentada no espírito africano tradicional de $U b u n t u^{5}$, para trabalhar os conflitos associados ao apartheid.

O objetivo dessa prática é realizar o empoderamento da comunidade para que essa consiga lidar com seus conflitos, assumindo a responsabilização pelo tratamento conflitivo e postura de governança dos recursos disponíveis para a consecução de uma sociedade plural e fraterna. (MEIRELLES \& YAZBEK, 2014)

Participam da prática restaurativa Zwelethemba, ou reunião de paz, as partes diretamente envolvidas no conflito, seus suportes e o facilitador. O suporte às partes é realizado por pessoas da família e da comunidade que possuam conhecimento do caso e, principalmente, capacidade para contribuir no tratamento do conflito possibilitando a redução da probabilidade da continuidade conflitiva.

A metodologia envolve a elaboração, por parte dos participantes de um "código de boas práticas", que irá fundamentar a atuação de todos. Dois âmbitos de pacificação são almejados: peace making e peace building. A primeira esfera da pacificação ocorre com a reparação dos danos decorrentes do comportamento ofensivo. A segunda atuação é um processo através do qual as instituições e organizações comunitárias são envolvidas nos encontros. Objetiva-se a construção em conjunto de plano-ação abrangente para que a comunidade possa lidar com o conflito.

No Brasil, tal prática foi utilizada em São Caetano do Sul/SP, no ano de 2006, no projeto intitulado "Comunidade e Justiça em parceria para a promoção de respeito e civilidade nas relações familiares e de vizinhança". (PEDROSO \& DAOU, 2014)

O projeto contou com treinamento de facilitadores e sensibilização da guarda municipal, conselho tutelar, equipe técnica do fórum, polícia militar e programa de saúde da família. Um dos os objetivos do projeto foi ampliar os canais para indicação de casos além da justiça criminal, assim buscou-se fortalecer os laços comunitários para o tratamento de eventos danosos.

\footnotetext{
${ }^{5}$ Termo sem definição exata no português, uma pessoa que possui ubuntu é alguém generoso, solícito e solidário. Assim, afirmar que uma pessoa tem ubuntu é um elogio. A comissão utilizou o termo em sentido amplo, para compila-lo aos direitos humanos e princípios restaurativos. A marca fundamental do processo sul-africano foi de que nessa cultura um crime nunca será um processo isolado, mas sim um fato que envolve a comunidade inteira e ameaça a estabilidade. (SICA, 2007, p. 103)
} 
A aplicação da prática restaurativa foi delineada através de treze fases: a) entrevista separada com as pessoas envolvidas no conflito; b) organização e encontro, nessa fase o facilitador encoraja as pessoas a participarem do encontro restaurativo comunitário; c) definição dos responsáveis pela condução do encontro, sendo que o ideal é que entre os dois facilitadores exista diferenças de idades ou profissões para refletir a diversidade da comunidade; d) abertura do encontro, oportunidade em que são esclarecidas as fases seguinte e modo de condução do trabalho; e) escuta-se o relato dos envolvidos na situação conflitiva; f) nova oportunidade de relato, podendo as partes complementarem as informações esclarecidas na etapa anterior; g) ocorre a participação da comunidade, possibilitando que pessoas que foram indiretamente afetadas pelo delito demonstrem os seus anseios e preocupação; h) identifica-se a raiz do problema, nessa fase trabalha-se com a compreensão do delito e suas causas, levando os envolvidos a refletir o que pode ser realizado para que o evento não se repita; i) cria-se um plano de ação; $\mathrm{j}$ ) as pessoas se comprometem com a realização do plano; k) realiza-se o registro dos dados relevantes para pesquisa; 1) encerra-se a reunião estimulando os presentes a demonstrar o reconhecimento da importância do plano de ação e da pacificação para a sociedade; $\mathrm{m}$ ) entrega dos registros para fins de análise dos dados do projeto.

A partir dos dados levantados, observou-se uma boa aceitação pelo projeto, mostrando um aumento da consciência e participação da comunidade para buscar soluções adequadas aos conflitos:

\footnotetext{
Segundo as facilitadoras a metodologia teve boa aceitação na comunidade, sua aplicação para a resolução de conflitos entre adultos tem surtido bons resultados à medida que, a versão de cada um é ouvida e considerada. A leitura do relato contribui para que a outra parte reflita sobre o que foi dito. Muitas vezes esta reflexão já produz mudanças, pois as pessoas nem sempre têm clareza do que gerou o conflito. A compreensão das razões do outro tem contribuído para o encontro de soluções. (PEDROSO \& DAOU, 2014, p. 175)
}

As práticas restaurativas possibilitam a clareza das informações. Um procedimento restaurativo pode ser frutífero mesmo que o acordo final não seja realizado. Isso, pois, muitas vezes a oportunidade de diálogo já gera ambiente de reaproximação na comunidade. E esse é um dos objetivos centrais da prática restaurativa Zwelethemba.

\subsection{ENCONTRO ENTRE VÍTIMA E OFENSOR}

Outra prática restaurativa amplamente utilizada é os encontros entre vítimasofensores. Conhecidos como VORP (Victim-Offender Reconciliation Programs), surgiram no 
Canadá e se estenderam para diversos países como Estados Unidos da América, Reino Unido, Áustria, Finlândia e Noruega. Estimava-se que em 2014 havia mais de trezentos programas do gênero na América do Norte e mais de quinhentos na Europa. (LEAL, 2014)

Inicialmente, trabalha-se com o ofensor e a vítima de maneira separada, assim fortalece-se o entendimento de cada um dos envolvidos do conflito. Caso as partes estejam preparadas para o encontro, passa-se à segunda fase do procedimento. (SANTOS \& GOMIDE, 2014)

Tal prática restaurativa difere das demais por limitar o encontro às partes diretamente afetadas pelo delito: autor e vítima. Consiste, assim, em um diálogo voluntário sobre o delito entre as partes principais, contando com a participação de um mediador. O objetivo do encontro é possibilitar com que a vítima expresse sua experiência, demonstrando as consequências do delito no plano físico, emocional e financeiro. O ofensor também tem a oportunidade de esclarecer os motivos que levaram à conduta, sua história de vida e admite a responsabilidade dos atos praticados.

\section{CONSIDERAÇÕES FINAIS}

A lógica restaurativa parte do entendimento que os conflitos devem ser tratados pelos próprios envolvidos, com o auxílio de terceiros. Os ideários restaurativos propõem um novo olhar para o tratamento dos conflitos, que permitem aos envolvidos a oportunidade de serem agentes transformadores da realidade social.

A ótica restaurativa não busca castigar e provocar novas rupturas sociais, ao contrário, se propõe a restaurar a harmonia e recompor os laços. O senso comunitário deve ser desenvolvido tendo como finalidade proceder de acordo com o melhor para todos. Essa atitude leva ao conceito de cidadania e de paz social.

O trabalho restaurativo se baseia na oitiva de narrativas, que demonstram a multiplicidade das interações humanas e a variedade de concepções de vida. A partir dessas concepções, os atos são realizados. Muitas vezes é necessário reconstruir signos (significados) para só depois poder falar em pacificação.

O elo estruturante da restauração é a formação da resposta justa a partir do encontro entre "eus" que se reconhecem e se aceitam como responsáveis. Difere assim, da justiça, dita tradicional, que determina o justo por decisão de um terceiro alheio ao conflito. Assim, os 
ideários restaurativos ressaltam a capacidade do ser humano em evoluir e amadurecer a partir das experiências de vida. A comunicação é um dos pilares restaurativos na medida em que permite que todos os que sofreram consequências com o conflito possam superar rótulos, e com isso libertar-se das lembranças e dores do evento danoso.

Como as práticas restaurativas apresentadas fundamentam-se no fortalecimento comunitário, a partir da responsabilização e entendimento das consequências dos eventos danosos nos casos concretos, gerando empatia e empoderamento das partes é possível concluir que tanto os círculos de construção de paz, quanto as conferências de grupos familiares, a metodologia Sul-Africana Zwelethemba e os encontros vítima-ofensor encontram-se plenamente alinhadas com o paradigma restaurativo.

Assim, a utilização de tais metodologias, amplia o ideário restaurativo, garantindo tanto a efetivação da dignidade da pessoa humana, como a solidariedade e a fraternidade. $\mathrm{O}$ paradigma restaurativo propicia uma forma de justiça participativa que opera uma real transformação, abrindo caminho para uma nova forma de promoção dos direitos humanos e de cidadania, da inclusão e da paz social.

\section{REFERÊNCIAS BIBLIOGRÁFICAS}

ACHUTTI, Daniel Silva. Justiça restaurativa e abolicionismo penal: contribuições para um novo modelo de administração de conflitos no Brasil. 2a ed. São Paulo; Saraiva, 2016.

BOONEN, Petronella Maria. A justiça restaurativa, um desafio para a educação. Tese (doutorado) - Faculdade de Educação da Universidade de São Paulo. Programa de PósGraduação em Educação, 2011.

FERRAO, Iara da Silva; SANTOS, Samara Silva dos; DIAS, Ana Cristina Garcia. Psicologia e Práticas Restaurativas na Socioeducação: Relato de Experiência. Psicol. cienc. prof., Brasília, v. 36, n. 2, p. 354-363, jun. 2016 . Disponível em <http://www.scielo.br/scielo.php?script=sci_arttext\&pid=S1414-

98932016000200354\&lng=pt\&nrm=iso $>$ acessos em $\quad 18 \quad$ jan. 2018. http://dx.doi.org/10.1590/1982-3703000122014.

FERREIRA, Francisco Amado. Justiça Restaurativa: natureza, finalidades e instrumentos. Coimbra: Coimbra Editora, 2006.

LEAL, César Barros. Justiça Restaurativa Amanhecer de uma Era: Aplicação em prisões e centros de internação de adolescentes infratores. Curitiba: Juruá, 2014. 
McCOLD, Paul; WACHTEL, Ted. Em busca de um paradigma: uma teoria de Justiça Restaurativa. Disponível em: http://www.realjustice.org/library_port.html. Acesso em 10 fev. 2007.

MEIRELLES, Cristina Assumpção e MARIONI, Marta dos Reis. Conferência de grupo familiar (FGC): projeto-piloto no sistema judiciário. (p. 233 - 248) In GRECCO, Aimée et al. Justiça Restaurativa em ação: práticas e reflexões. São Paulo: Dash, 2014.

MEIRELLES, Cristina Assumpção e YAZBEK, Vania Curi. Formatos conversacionais nas metodologias restaurativas. (p. 109 - 125) In GRECCO, Aimée et al. Justiça Restaurativa em ação: práticas e reflexões. São Paulo: Dash, 2014.

MORIN, Edgar, PRIGOGINE, llya e outros. A sociedade em busca de valores: para fugir à alternativa entre o cepticismo e o dogmatismo. Trad. Luís M. Couceiro Feio. Lisboa: Instituto Piaget, 1996.

PEDROSO, Heloise Helena e DAOU, Violeta. Metodologia Zwelwthwmba e sua aplicabilidade na comunidade de São Caetano do Sul - São Paulo, Brasil. (p. 161 - 180) In GRECCO, Aimée et al. Justiça Restaurativa em ação: práticas e reflexões. São Paulo: Dash, 2014.

PRANIS, Kay. Processos Circulares. Trad. Tônia Van Acker. São Paulo: Palas Athena, 2010.

SANTOS, Cláudia Cruz. A Justiça Restaurativa: um modelo de reação ao crime diferente da Justiça Penal - Porquê, para quê e como? Coimbra: Coimbra Editora, 2014.

SANTOS, Mayta Lobo dos e GOMIDE, Paula Inez Cunha. Justiça restaurativa na escola: aplicação e avaliação do programa. Curitiba: Juruá, 2014.

SICA, Leonardo. Justiça Restaurativa e Mediação Penal. Rio de Janeiro: Lumen Júris, 2007.

SUMALLA, Josep Tamarit. La articulación de la justicia restaurativa con el sistema de justicia penal. (p. 61-88) In SUMALLA, Josep Tamarit (org). La Justicia Restaurativa: Desarrollo y Aplicaciones. Granada: Editorial Comares, 2012.

SUMALLA, Josep Tamarit. La justicia restaurativa: concepto, princípios, investigación y marco teórico. (p. 3-60) In SUMALLA, Josep Tamarit (org). La Justicia Restaurativa: Desarrollo y Aplicaciones. Granada: Editorial Comares, 2012.

ZERH, Howard. Justiça Restaurativa. Trad. Tônia Van Acker. $2^{a}$ ed. São Paulo: Palas Athena, 2017.

ZERH, Howard. Trocando as lentes: um novo foco sobre o crime e a justiça. Trad. Tônia Van Acker. 2 ed. São Paulo: Palas Athena, 2014. 